saving life even in the attempt at removing it by the knife. Some four years after (1533), the author was met by the uncle of the little patient, who told him she was grown a fine bouncing girl, and with scarcely a visible mark left of the former disease.

Six years ago it was the intention of the author to bave given a series of cases to THE Lancet, but severe and protracted illness prevented him from accomplishing this object. For the present, however, the trusts that these minutes will be sufficient to awaken the serious consideration both of the profession and the public. Other cases, formidable in their nature and highly inte. resting, are now going on successfully under the treatment.

\section{TINNITUS AURIUM.}

\section{To the Editor of THE LANCET.}

SrR:-Tinnitus aurium, one of the most distressing symptoms to which persons with impaired hearing are liable, is at the same time one of the most dificult to remove. When it is considered that tinnitus is a symptom indicative of various morbid conditions of the parts engaged in the function of hearing, some of which are diametrically opposite the one to the other, as I shall presently show, it will be evident that much attention and discrimination will be requisite to trace it to its real source, and to apply the proper treatment. Tinnitus is dependent in almost every instance on constitutional causes, and can rarely be even alleviated by any measures, which are not directed to improve the general health. It occasionally accompanies a diseased state of the cerumen; this secretion being either in excess, or else greatly deficient. It is also occasionally found as the precursor of apoplexy, in which case the noises are heavy and dull; the other symptoms, which are present, will indicate the nature of the case to the expe. rienced physician.

The following extract from a work on the Preservation of Hearing by M. Schmulz, of Dresden, with a copy of which I was pre.sented by the author when $I$ was in that city, will show the importance of this symptom, and the annoyance which results from its presence :-

"Le bruissement est en général une incommodité aussi pénible qu'opiniâtre, qui trouble, du moins au commencement, la pensée, et absorbe l'attention du malade, vu que celui-ci l'y porte involontairement. Parmi les indispositions, auxquelles nous sommes sujets, il est du nombre de celles, que le temps et l'babitude adoucissent le moins. Les personnes, qui en souffrent, tombent presque toujours dans une profonde tristesse, et le bruissement les tourmente souvent beaucoup plus que la dureté d'oreille, aussi long temps, du moins, que celle-ci n'a pas atteint un trop haut grade. Du reste, c'est par ce symptôme que commencent la plupart des affections de l'ouie dont nous allons parler, et c'est très souvent la première marque, à laquelle on reconnaît une maladie commençante de cet organe."

Tinnitus aurium is generally symptomatic of a disordered and weakened state of the general nervous system, more especially of the ganglionic apparatus, when the auditory nerve suffers in common with other parts of the body; under such circumstances, the disordered appetite, the irregularity of the circulation, as evidenced by the state of the pulse and palpitations of the heart; the im. pairment of the other sensorial functions, as vision, smell, \&c., the secretions being generally imperfectly performed, and the manifest derangement of the whole nervous system, will sufficiently indicate to the cautious observer the proximate cause of the symptom I allude to. The predisposing causes are, intemperance, irregularity of living, profuse discharges, depressing passions, and, in short, whatever will weaken the frame, and greatly diminish or exhaust the nervous power: whatever will improve the general health, impart energy to the nervous system, and tone to the frame, will be of service in removing this variety of tinnitus. With this view, I have prescribed a combination of the arnica montana root combined with valerian and cinchona, administered twice a-day: I commence with three grains of the arnica, and gradually increase the dose to seven. The quantity of valerian and cinchona will, of course, be regulated by the symptoms; an infusion of the arnica with cascarilla and valerian has been occasionally employed, and with equal advantage: under its use, the general bealth has improved, the appetite has become better and more regular, the patient has acquired strength, and the distressing nervous sensatious, including the tinnitus, have gradually disappeared. The arnica is a remedy which has been admitted and expelled, and readmitted and re-expelled the pharmacopoeia, chiefly, I believe, because its utility was not sufficiently known. It was formerly called doronicum Germanicum. It has been ased in fevers, particularly of the intermittent kind, and in gangrene, in which cases it is said to have been as efficacious as cinchona; a remedy of such importance should not be allowed to fall into oblivion. The neglect with which it has been treated, has probably arisen from the fact that its use is not attended in many instances with any sensible operation, although it occasionally callses vomiting, diaphoresis, or diuresis ; Hallei says, that even gutta serena has yielded to the powers of this medicine; I have occasionally employed the lactate and citrate of iron in these cases, and have reason to be much pleased with the results. These preparations of iron I prefer to those in ordinary 
use, as they are less liable to affect the head.

Dr. Linke, of Leipsic, is of opinion, that tinnitus aurium affecting the left ear only is connected with a diseased condition of the liver; and he told me that the results of the cadaveric examinations he had instituted confirmed him in his opinion. He bad not been able to trace a similar connection between tinnitus of the right ear and that viscus. My own opinion is, that tinnitus is dependent on a disordered state of the ganglionic or trisplanchnic system of nerves, and to be removed by attention to the general health, improving the secretions, and restoring the tone of the system generally. In this opinion, I am happy to say, I am supported by Dr. Carus, physician to the King of Saxony, and by Dr: Boehm, physician to the principal hospital at Berlin. The following extract on aural neurology, from a work by Dr. S. Pappenheim, of Breslau, in Silesia, which was recommended to me by Dr. Carus, contains, as I think, some useful information respecting the ganglionic condition of the nerves of the internal ear :"The nerves of the internal ear are the nervus acousticus, the portio intermedia Wrisbergii, the anastomosing branch of the facialis and acousticus; the branches of the auditory nerve, viz., the nervi cochleæ and vestibuli, the ampullaris saccularis, \&c.; which last forms a small ganglionic swelling, from which three bundles spring, which, according to their situation, are divided into a superior, middle, and inferior. The auditory nerve is cerebro-spinal in man and the domestic animals only. The anastomosing branch of the facialis and acousticus is provided with a ganglion in the ox, and consists of many ganglionic globuli. This branch may be traced backwards, and isolated as a small stem in the sheath of the acoustic nerve : it springs from the acoustic and passes to the facialis, where it is enlarged by additional fibres. The nervus cochlex is totally covered on its upper surface by a broad reddish-grey stratum, which consists of ganglionic globuli. The nervus vestibuli has, particularly on its posterior aud outer surface, a reddish ganglionic substance. The nervus modioli contains ganglia in the human subject."

After the distinct account $I$ have given of the symptoms and treatment of tinnitus, it cannot be necessary, in alluding to a few cases, to do more than give a brief outline thereof.

Elizabeth Lumbless, ætat. 62, a nurse, has been annoyed with tinnitus for five years, accompanied with nervous deafness. Her health generally is out of order, by attending to which, and by the use of the arnica for three weeks, she got rid of the noises, and her deafness was much lessened.

Thomas Wright, xtat. 66, has been afflicted with tinnitus for some time, but cannot say for how long: was a sergeant in the 44 th regiment of foot, and served with Abercrombie in Egypt, where be was wounded. The same remedies afforded him decided relief.

Rebecca Garden, ztat. 40, a widow with four children, troubled with deafness and tinnitus ever since she lost her husband, about three years since: the noises are so troublesome, she cannot sleep at night; is very much out of health, but the catamenia are regular. She was cured of her deafness by the measures usually adopted at the dis. pensary; but the noises continued, and were ultimately removed by the use of aperient medicines, conjointly with arnica.

A young lady from the city, affected with tinnitus, in consequence of the death of her brother by drowning, is very low spirited and hypochondriacal; the catamenia irregular; has been under medical treatment, but in all probability without attending to directions. In this case the lactate of iron was administered in conjunction with the arnica; the health gradually improved, the catamenja returned, and my interesting patieut, I am happy to say, got well.

Captain S., ztat. 42 , a free liver, has been a good deal abroad; attributes his affliction to a cold caught on leaving a warm bath. He was cured by an infusion of arnica, one drachm to six ounces, with tincture of columba, of which he took three tablespoons. ful three times a-day. I remain, \&c.

John Harrison Curtis,

Surgeon to the Royal Dispensary for Diseases of the Ear.

2, Soho-square, Aug. 26, 1841.

\section{MALIGNANT DISEASE OF THE PENIS.}

\section{To the Editor of $\mathbf{T} \mathrm{HE}$ LANCET.}

SIR:-The case of malignant disease of the penis which you inserted in your Journal of July 31 , page 655 , has turned out differently to what I anticipated, although the appearances then were most favourable, the wound after amputation having healed perfectly in three weeks. It was on the day after I sent you the report of the case that he complained of violent pains in the inguinal glands, which soon enlarged, and went on rapidly to ulceration, and the whole left inguinal region is now one frightful mass of fungoid ulcers; he emaciates very fast, and is rapidly sinking.

I have thought it well to send you this statement for those of your numerons readers who may have read the case as reported before. I have the honour to be, Sir, your obedient servant,

Stourbridge, August 18, 1841. 